\title{
Five-year experience in using coil embolization for ruptured intracranial aneurysms: outcomes and incidence of late rebleeding
}

James V. Byrne, M.D., F.R.C.S., F.R.C.R., Min-Joo Sohn, M.Sc., and Andrew J. Molyneux, M.B., B. Chir, F.R.C.R.

University Department of Radiology, The Radcliffe Infirmary National Health Service Trust, Oxford, England, United Kingdom

Object. During a 5-year period 317 patients presenting with aneurysmal subarachnoid hemorrhage were successfully treated by coil embolization within 30 days of hemorrhage. The authors followed these cases to assess the stability of aneurysm occlusion and its longer-term efficacy in protecting patients against rebleeding.

Methods. These cases were followed for 6 to 65 months (median 22.3 months) by clinical review, angiography performed at 6 months posttreatment, and annual postal questionnaires.

Conclusions. Stable angiographic occlusion was evident in $86.4 \%$ of small and $85.2 \%$ of large aneurysms with recurrent filling in 38 (14.7\%) of 259 aneurysms. Rebleeding was caused by aneurysm recurrence in four patients (between 11 and 35 months posttreatment) and by rupture of a coincidental untreated aneurysm in one patient. Annual rebleeding rates were $0.8 \%$ in the 1 st year, $0.6 \%$ in the 2 nd year, and $2.4 \%$ in the 3rd year after aneurysm embolization, with no rebleeding in subsequent years. Rebleeding occurred in three (7.9\%) of 38 recurrent aneurysms and in one $(0.4 \%)$ of 221 aneurysms that appeared stable on angiography. Periodic follow-up angiography after coil embolization is recommended to identify aneurysm recurrence and those patients at a high risk of late rebleeding.

Key Words * aneurysm * embolization * subarachnoid hemorrhage * Guglielmi detachable coil * rebleeding * clinical outcome

In the last decade, endosaccular packing with coils has become established as the preferred endovascular method for the treatment of intracranial aneurysms.[8,23,42] The introduction of detachable coils, such as the Guglielmi detachable coil (GDC; Target Therapeutics, Fremont, CA) has stimulated the treatment's widespread use and extended its indications to include aneurysms that previously would have been treated by craniotomy and microsurgical clipping.[5,18-20,33,34,36,46,48,54] Indications now include patients presenting soon after aneurysm rupture.[7,17,40,55] Although no randomized data has been published, observational studies have reported clinical outcomes after aneurysmal subarachnoid hemorrhage (SAH) that are comparable to those of conventional microsurgical clipping in the short term. $[7,17,40,55]$ These studies suggest that treatment provides protection against aneurysm rebleeding 
in the first few months after rupture,[7,17,30,40] when rebleeding is most frequent.[56] However, aneurysm recurrence may occur as a result of subtotal packing or compaction of the coil-thrombus complex,[14,24] which raises concerns about the ability of coil embolization to protect against aneurysm regrowth and/or rerupture in the long term.[4,30,42]

To date, reports of patients treated by coil embolization for intracranial aneurysms have concentrated on short-term efficacy and procedural safety. The larger series generally include patients presenting with both ruptured and unruptured aneurysms $[5,9,30,40,46]$ or do not provide details of follow-up angiography and long-term outcome.[4,7,41,55] This study was performed to provide data on the stability of endosaccular packing of ruptured aneurysms during the acute phase by using GDCs over the first 6 months posttreatment and its long-term efficacy in protecting against rebleeding. Such data are needed to establish follow-up protocols and the place of this novel technology in the management of aneurysmal SAH.

\section{CLINICAL MATERIAL AND METHODS}

During a 5-year period (July 1992-June 1997) 465 patients underwent endovascular treatment for intracranial aneurysms. This study involves 317 of these patients who were successfully treated during the acute phase after suffering aneurysmal SAH. The study population was composed of 191 women (60.3\%) and 126 men (39.7\%). The mean age of the patients at presentation was 50.5 years (range 22-82 years). The age distributions by decade are presented in Table 1 . The entry criteria for patients included: 1) a clinical diagnosis of SAH supported by either computerized tomography scanning or a xanthochromic cerebrospinal fluid sample, and 2) coil embolization by endosaccular packing performed within 30 days of the last hemorrhage, which successfully occluded the aneurysm. Patients who had undergone an unsuccessful craniotomy and attempted clipping of a ruptured aneurysm were included in this definition. The other 148 patients treated during this period were excluded from the study because they were treated for unruptured aneurysms or were treated more than 30 days after their last SAH.

\begin{tabular}{|cc|}
\hline TABLE 1 \\
\hline AGES OF 317 PATIENTS AT TREATMENT STRATIFIED BV DECADE \\
\hline \hline Age (Mrs) & No. of Patients (\%) \\
\hline$\times 20$ & $0(0)$ \\
$20-29$ & $10(3.2)$ \\
$30-39$ & $35(11)$ \\
$40-49$ & $101(31.9)$ \\
$50-59$ & $110(34.7)$ \\
$60-69$ & $45(14.2)$ \\
$70-79$ & $13(4.1)$ \\
\hdashline 80 & $3(0.9)$ \\
total & $317(100)$ \\
\hline
\end{tabular}

Selection of patients for coil embolization rather than surgical clipping was made by consultation between a neurosurgeon and an interventional neuroradiologist. At the start of the study, only patients considered to be at high risk for surgical clipping were recruited, usually on the basis of aneurysm location (such as posterior circulation or carotid ophthalmic aneurysms) or poor clinical status due to the $\mathrm{SAH}$, a coexisting medical condition, or extreme old age. An angiographic assessment of the aneurysm's suitability for endovascular treatment was made. The criteria were that the neck of the aneurysm was sufficiently discrete to retain coils and that treatment could be performed without compromising the 
parent or adjacent artery. Since 1994 some patients with anterior circulation aneurysms that were clippable and in whom clinical equipoise existed after the aforementioned assessments were offered entry into an ongoing multicenter randomized trial (International Subarachnoid Aneurysm Trial [ISAT]). After informed consent was obtained, these patients were randomly allocated to endovascular treatment or surgery.

Coil embolization was performed as soon as possible after admission to our institution. The procedures were performed within 2 days of aneurysm rupture in 91 patients $(28.7 \%)$ and within 2 weeks in 253 patients (79.8\%) (Table 2). Because referrals were made by both local and distant neurosurgeons, the series includes a relatively high proportion of good-grade patients, reflecting a tendency to restrict transfer to patients who were well enough to travel. Because of inevitable delays, clinical status was recorded using the World Federation of Neurosurgical Societies (WFNS) grading score[10] at the time of treatment rather than at the time of admission (Table 2). Endovascular treatment was performed using GDCs to pack the body of the aneurysm sac as densely as possible and, thereby, obstruct the neck. Our technique and procedure protocol have been previously described.[7] In patients with multiple aneurysms, the aneurysm believed to have caused the hemorrhage was treated first and coincidental aneurysms were treated during the same procedure or subsequently by either GDC embolization or surgical clipping.

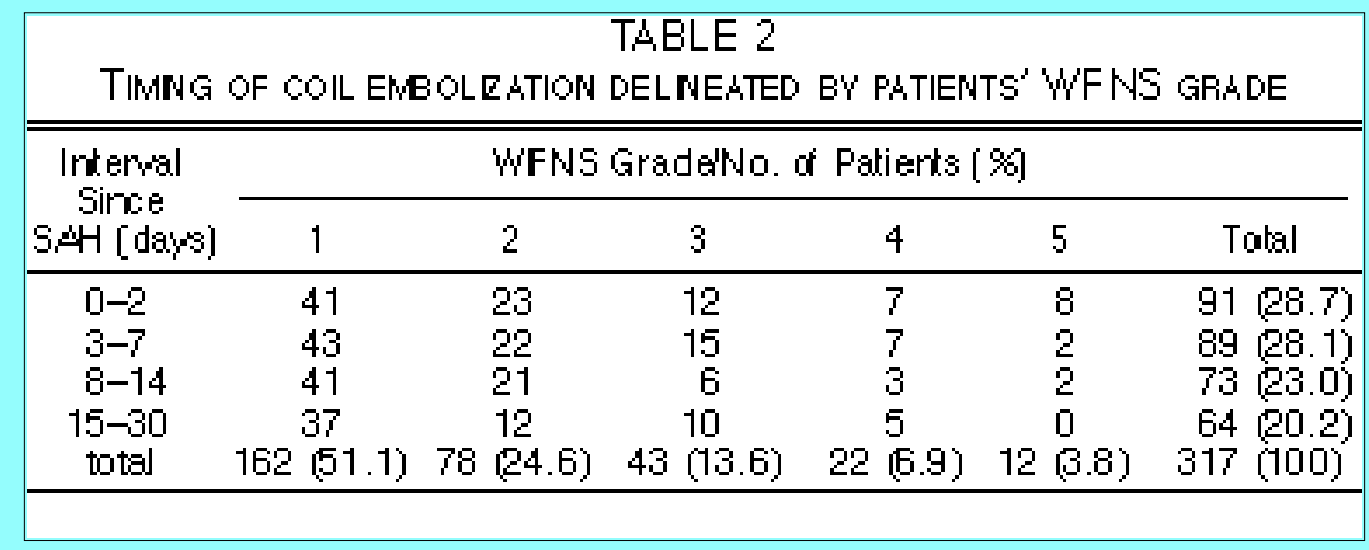

The locations of the aneurysms assumed to have ruptured are presented in Table 3. The termination (or bifurcation) of the BA was the most common location with 76 aneurysms (24\%); 111 aneurysms (35\%) were located in the posterior cerebral circulation. The primary aneurysm was treated in one session in all but two patients in whom treatment required two sessions. 


\begin{tabular}{|c|c|c|c|c|}
\hline LOC & $\begin{array}{r}\text { NS AND SIZE } \\
\text { BV }\end{array}$ & $\begin{array}{l}\text { ABLE } 3 \\
\text { RU PTURED } \\
\text { EMBOLIZATI }\end{array}$ & RVSMS T & \\
\hline & & ysm SizeN & netrysms & \\
\hline Site & Small & Large & Giart & Total \\
\hline $\mathrm{ICA}$ & & & & \\
\hline $\begin{array}{l}\mathrm{COA} \\
\mathrm{PCOA}\end{array}$ & $\begin{array}{r}6 \\
32\end{array}$ & $\begin{array}{r}7 \\
11\end{array}$ & $\begin{array}{l}0 \\
1\end{array}$ & $\begin{array}{l}13(4.1) \\
44(13.9)\end{array}$ \\
\hline $\begin{array}{l}\text { Other } \\
\mathrm{ACA}\end{array}$ & 4 & 10 & 0 & $14(4.4)$ \\
\hline $\begin{array}{l}\text { prosimal } \\
\mathrm{BOOA}\end{array}$ & $\begin{array}{r}1 \\
54\end{array}$ & $\begin{array}{r}3 \\
16\end{array}$ & $\begin{array}{l}0 \\
0\end{array}$ & $\begin{array}{r}4(1.3) \\
70(22.1)\end{array}$ \\
\hline Distal & 7 & 2 & 0 & $9(2.8)$ \\
\hline $\begin{array}{l}\text { bifurcation } \\
\text { other }\end{array}$ & ${ }_{8}^{27}$ & $\begin{array}{r}12 \\
1\end{array}$ & $\begin{array}{l}1 \\
0\end{array}$ & $40(12.6)$ \\
\hline $\begin{array}{l}\mathrm{PCA} \\
\mathrm{BA}\end{array}$ & 2 & 1 & 0 & $3(0.9)$ \\
\hline $\begin{array}{l}\text { termination } \\
\text { trunk }\end{array}$ & $\begin{array}{l}46 \\
11\end{array}$ & $\begin{array}{r}27 \\
7\end{array}$ & $\begin{array}{l}3 \\
0\end{array}$ & $\begin{array}{l}76(24) \\
18(5.7)\end{array}$ \\
\hline $\begin{array}{l}\text { VA } \\
\text { PICA } \\
\text { other } \\
\text { total }\end{array}$ & $\begin{array}{c}13 \\
1 \\
212(66.9) \\
\end{array}$ & $\begin{array}{c}1 \\
1 \\
99(31.2) \\
\end{array}$ & $\begin{array}{c}0 \\
1 \\
6(1.9) \\
\end{array}$ & $\begin{array}{r}14(4.4) \\
3(0.9) \\
317(100)\end{array}$ \\
\hline $\begin{array}{l}\text { "Ane urysms } \\
\text { mm) on the be } \\
\text { rior cerebral a } \\
\text { COA = carotic } \\
\text { cerebral arter } \\
\text { cating artery; }\end{array}$ & $\begin{array}{l}\text { fined as } \\
\text { their maxi } \\
\text { oo } \mathrm{A}=\mathrm{an} \\
\mathrm{almic} \text { art } \\
=\text { posten } \\
\text { nosterior }\end{array}$ & $\begin{array}{l}(10 \mathrm{~mm}) \text {, } \\
\text { ac dim en }\end{array}$ & $\begin{array}{l}10-25 \text { I } \\
\text { bbrevia } \\
\text { itery, } \\
\text { tid arte } \\
\text { on }=F \\
\text { ry }\end{array}$ & $\begin{array}{l}\text { giant } \infty 25 \\
\text { ch } A=\text { ante } \\
\text { silar artery } \\
\mu=\text { middle } \\
\text { communi- } \\
\text { oral artery }\end{array}$ \\
\hline
\end{tabular}

Multiple aneurysms were present in 83 patients (26.2\%); the site details of these aneurysms are presented in Table 4. Eight of these patients had three aneurysms, four patients had four, one patient had five, and one patient had six aneurysms. In all, 97 coincidental aneurysms were diagnosed. Forty-seven of these aneurysms were treated during the study period: 43 by coil embolization and four by microsurgical clipping. 


\begin{tabular}{|c|c|c|c|c|c|c|}
\hline \multicolumn{7}{|c|}{$\begin{array}{c}\text { TABLE } 4 \\
\text { LOCATIONS OF COINCDENTAL UNRUPT }\end{array}$} \\
\hline \multirow{2}{*}{$\begin{array}{l}\text { Aneurysm } \\
\text { Site }\end{array}$} & \multicolumn{6}{|c|}{ No. of Coincidertal Ane urysms (\%) } \\
\hline & 1 & 2 & 3 & 4 & 5 & Tatal \\
\hline \multicolumn{7}{|l|}{ ICA } \\
\hline COA & $\begin{array}{r}4 \\
21\end{array}$ & $\overline{1}$ & $\overline{1}$ & - & 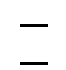 & $4(4.1)$ \\
\hline other & 13 & 2 & 1 & 1 & - & $17(17.5)$ \\
\hline ACA & & & & & & \\
\hline $\begin{array}{l}\text { proximal } \\
\mathrm{ACOA}\end{array}$ & $\begin{array}{l}3 \\
5\end{array}$ & - & - & - & $\bar{z}$ & $\begin{array}{l}3(3.1) \\
5(5.2)\end{array}$ \\
\hline \multirow{2}{*}{\multicolumn{7}{|c|}{ MCA }} \\
\hline & & & & & & \\
\hline provimal & 2 & 1 & 1 & - & - & $4(4.1)$ \\
\hline $\begin{array}{l}\text { bifurcation } \\
\text { distal }\end{array}$ & 20 & 2 & 1 & - & - & $23(23.7)$ \\
\hline \multicolumn{7}{|l|}{ BA } \\
\hline termination & 5 & - & - & - & - & $5(5.2)$ \\
\hline trunk & 2 & 1 & - & - & - & $3(3.1)$ \\
\hline \multicolumn{7}{|l|}{ VÁ } \\
\hline total & 83 & 8 & 4 & 1 & 1 & $97(100)$ \\
\hline
\end{tabular}

Cases were followed by clinical review and repeated intraarterial angiography at 6 months, although in some patients angiography was performed between 6 and 12 months after completion of treatment, in others it was conducted earlier (2-3 months) because of concern about the completeness of the embolization at the time of treatment. Thereafter, patients were contacted by mail and asked to fill out follow-up questionnaires. Specific inquiry about further intracranial hemorrhage was made and patients, their families, or their referring physicians were contacted to provide details of current status in patients who failed to respond to the questionnaire. The questionnaire design was based on that used in the International Stroke Trial (IST) and ISAT to collect a modified Rankin score, with a Rankin score of 0 or 1 being assigned Glasgow Outcome Scale[25] (GOS) score 5, Rankin score 2 assigned GOS score 3, Rankin score 3 or 4 assigned GOS 3, and Rankin score 5 assigned GOS score 2. Patients who died were assigned a GOS score of 1 . This instrument has been validated in the IST.[28]

Patients remained in the study until they died, rebleeding occurred, or surgical clipping or arterial occlusion was performed in the management of recurrence. In the first 30 days postprocedure, 11 patients died and four patients who were discharged from the hospital in satisfactory condition were lost to follow-up review. During the period of 1 to 6 months posttreatment, five patients died, one due to rebleeding (Case 1) and four of causes unrelated to the procedure. Follow-up periods were calculated for each patient as the number of days between the treatment date and the date of last contact. These data were used to calculate Kaplan-Meier graphs for survival time and rebleeding-free survival time. The risk of rebleeding during the study period was, thereby, calculated for each patient's follow-up year and related to the number of patients at risk of rebleeding. The longest follow-up time was 1982 days (65 months), median 670.5 days (22.3 months).

\section{RESULTS}

\section{Clinical Outcome}


In the 313 patients for whom we have data, clinical outcomes at 6 months were as follows: 199 patients (63.5\%) made complete recoveries (GOS score 5), 56 (17.9\%) made good recoveries (GOS score 4), 31 $(9.9 \%)$ were moderately disabled (GOS score 3), 11 (3.5\%) were severely disabled (GOS score 2) and 16 $(5.1 \%)$ had died (GOS score 1$)$. These outcomes and relevant pretreatment WFNS grades are presented in Table 5. In this series there was a relatively high proportion of patients classified as WFNS Grade 1 compared with WFNS Grade 2, which reflects the difficulty sometimes experienced in separating these grades. For this reason the two have been amalgamated for analysis. Excellent or good outcomes measured at 6 months posttreatment were achieved in $87.8 \%$ of patients with WFNS Grades 1 and 2, in $71.4 \%$ of patients with WFNS Grade 3, and in $48.5 \%$ of patients with WFNS Grades 4 and 5 at the time of treatment; overall excellent or good outcomes were achieved in $81.5 \%$ of patients. The mortality rates (all causes) at 6 months posttreatment were $4.3 \%$ (95\% confidence interval [CI] 1.8-6.4\%) for patients with WFNS Grades 1 to 3; $12.1 \%$ (95\% CI 0.9-23\%) for patients with WFNS Grades 4 and 5; and 5.1\% (95\% CI 2.6-6.3\%) for all patients.

\begin{tabular}{|lrccccc|}
\hline \multicolumn{7}{|c|}{ TABLE 5 } \\
COMPARISON OF PATIENTS' GOS SCORES AND WFNS GRADES AT \\
TIME OF TREATMEN T*
\end{tabular}

Angiographic assessment of the degree of occlusion was made in 259 aneurysms in $250(84.2 \%)$ of the available 297 patients between 6 and 12 months after coil embolization. Some of the patients were not studied because they were in a poor grade and it was judged inappropriate because additional treatment would not be recommended, the patient had returned to a foreign country, or the patient refused further assessment. The findings, according to aneurysm size, are presented in Table 6. 


\begin{tabular}{|c|c|c|c|c|c|}
\hline \multicolumn{6}{|c|}{$\begin{array}{l}\text { DISTRIBUTON OF ANEURVSMS ON FOLLOW-UP INTRAARTERIAL } \\
\text { ANGOGRA PHY ACCORD NG TO ANEURVSM SIZE AND } \\
\text { PERCENTAGE OF OCCLUSION AT END OF TREATMENT }\end{array}$} \\
\hline \multirow{2}{*}{$\begin{array}{l}\text { No. of } \\
\text { Anetrysm Size }\end{array}$} & \multirow[b]{2}{*}{ Anetrysms } & \multicolumn{4}{|c|}{$\begin{array}{l}\text { Percentage of Occl usion at End } \\
\text { of Treatm entw } 0 \text {. of Patients }[\%]\end{array}$} \\
\hline & & 100 & 95 & $<95$ & Total \\
\hline small & $176(60 \%)$ & & & & \\
\hline $\begin{array}{l}\text { stable on FU } \\
\text { recurrence on FU } \\
\text { subtotal }\end{array}$ & & $\begin{array}{r}101 \\
16 \\
117\end{array}$ & $\begin{array}{r}47 \\
8 \\
55\end{array}$ & $\begin{array}{l}4 \\
0 \\
4\end{array}$ & $\begin{array}{r}152(86.4) \\
24(13.6) \\
176(100)\end{array}$ \\
\hline large & $81(31 \%)$ & & & & \\
\hline $\begin{array}{l}\text { stable on FU } \\
\text { recurrence on FU } \\
\text { subtotal }\end{array}$ & & $\begin{array}{r}40 \\
7 \\
47\end{array}$ & $\begin{array}{r}28 \\
53\end{array}$ & $\begin{array}{l}1 \\
0 \\
1\end{array}$ & $\begin{array}{l}69(85.2) \\
12(14.8) \\
81(100)\end{array}$ \\
\hline giant & $2(1 \%)$ & & & & \\
\hline $\begin{array}{l}\text { stable on FU } \\
\text { recurrence on FU }\end{array}$ & & $\begin{array}{l}0 \\
1\end{array}$ & $\begin{array}{l}0 \\
1\end{array}$ & 0 & $\begin{array}{l}0(0) \\
2(100)\end{array}$ \\
\hline subtotal & & 1 & 1 & 0 & $2(100)$ \\
\hline
\end{tabular}

Following treatment $165(64 \%)$ of these 259 aneurysms were completely occluded, $89(34 \%)$ had a small remnant (> 95\% occlusion), and five $(2 \%)$ had more substantial residual filling ( $<95 \%$ occlusion). Recurrence (or unstable occlusion) was defined as an increase in the amount of contrast filling the aneurysm relative to the end-of-treatment angiographic appearance of the aneurysm. An aneurysm was classified as stable at follow-up review if the degree of occlusion was unchanged or had improved relative to the end-of-treatment study. Stable occlusions were present in $86.4 \%$ of the small aneurysms, $85.2 \%$ of the large aneurysms, and neither of the two giant aneurysms. Overall, 221 aneurysms (85.3\%) remained stable and $38(14.7 \%)$ enlarged to some degree. As well as recurrence, angiography demonstrated improved degrees of occlusion in 22 aneurysms (8.5\%) (11 small and 11 large) due to thrombosis subsequent to the completion of packing with coils and the reversal of periprocedural anticoagulation. Recurrent aneurysms were treated with endovascular coil or balloon occlusion of the aneurysm-bearing artery in 11 patients; two patients underwent surgical clipping and two patients refused further treatment. The remaining patients continue to be observed.

\section{Rebleeding}

Five patients suffered recurrent spontaneous SAH. These events occurred between 5 and 35 months after coil embolization. Details on the patients and their aneurysms are listed in Table 7. 
TABLE 7

PATENTS WITH REBLEEDING*

\begin{tabular}{|c|c|c|c|c|c|c|c|c|}
\hline $\begin{array}{l}\text { Case } \\
\text { No. }\end{array}$ & $\begin{array}{l}\text { Age } \\
\text { (yrs), } \\
\text { Sex }\end{array}$ & $\begin{array}{l}\text { Aneurysm } \\
\text { Site(s) }\end{array}$ & $\begin{array}{l}\text { Aneu- } \\
\text { ysm } \\
\text { Size }\end{array}$ & $\begin{array}{l}\text { Finding } \\
\text { on } 6 \text { twio } \\
\text { Angiogam }\end{array}$ & $\begin{array}{l}\text { Time to } \\
\text { Retl eed- } \\
\text { ing (mos) }\end{array}$ & $\begin{array}{l}\text { Re- } \\
\text { treat- } \\
\text { mert. }\end{array}$ & $\begin{array}{l}\text { Out- } \\
\text { come }\end{array}$ & Comment \\
\hline 1 & $49, F$ & $\begin{array}{l}\text { BA termination } \\
\text { MCA (lt) } \\
\text { MCA (rt) } \\
\text { PCoA (rt }\end{array}$ & $\begin{array}{l}\text { small } \\
\text { small } \\
\text { small } † \\
\text { small }\end{array}$ & not performed & 5 & no & died & $\begin{array}{l}\text { CT scan revealed } \\
\text { rebleeding from } \\
\text { untreated aneurysm }\end{array}$ \\
\hline 2 & $72, \mathrm{~F}$ & distal ÁCA & small & recurrence & 18 & no & died & $\begin{array}{l}\text { patient refused re- } \\
\text { treatment at } 6 \text { mos }\end{array}$ \\
\hline 3 & $64, F$ & ICÁ termination & large & stable rem nant & 11 & yes & good & $\begin{array}{l}\text { recurrenoe at time of } \\
\text { rebleeding }\end{array}$ \\
\hline 4 & $58, F$ & $\mathrm{BA}$ termination & large & small recurrence & 30 & yes & good & $\begin{array}{l}\text { further recurrence at } \\
\text { time of rebleeding }\end{array}$ \\
\hline 5 & $56, F$ & PCOA & small & recurrence & 35 & yes & good & $\begin{array}{l}\text { additional angiogra- } \\
\text { phy scheduled at } \\
\text { time of rebleeding }\end{array}$ \\
\hline
\end{tabular}

Rebleeding in Case 1 was caused by rupture of a coincidental untreated aneurysm. In Case 2, angiography revealed recurrence of a pericallosal aneurysm at the 6-month follow-up angiography session (Fig. 1). The patient declined further treatment and suffered a fatal rebleeding 18 months after the original treatment.

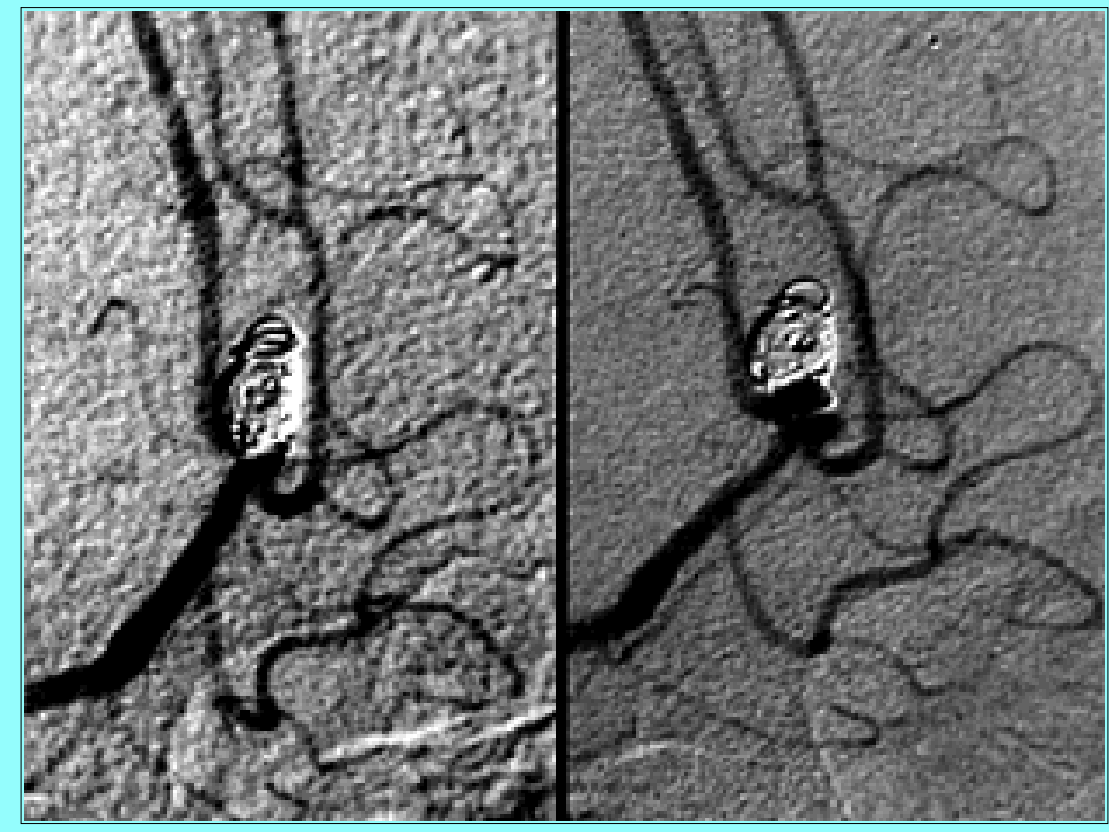

Fig. 1. Case 2 (Table 7). Intraarterial subtraction angiograms demonstrating a small distal ACA aneurysm following coil embolization (left) and 6 months later (right). Recurrent filling was due to compaction of coils at the aneurysm neck. The patient declined further treatment.

The patient in Case 3 underwent two attempts to clip a large terminal internal carotid artery aneurysm before being referred for coil embolization. Stable residual filling of the aneurysm was evident at 6 months; however, this extended with recurrence of the aneurysm at the time of rebleeding 5 months later. 
The patients in Cases 4 and 5 were found to have some aneurysm reopening on their 6-month follow-up angiograms, which had enlarged substantially by the time of rebleeding 24 and 29 months later, respectively (Fig. 2).

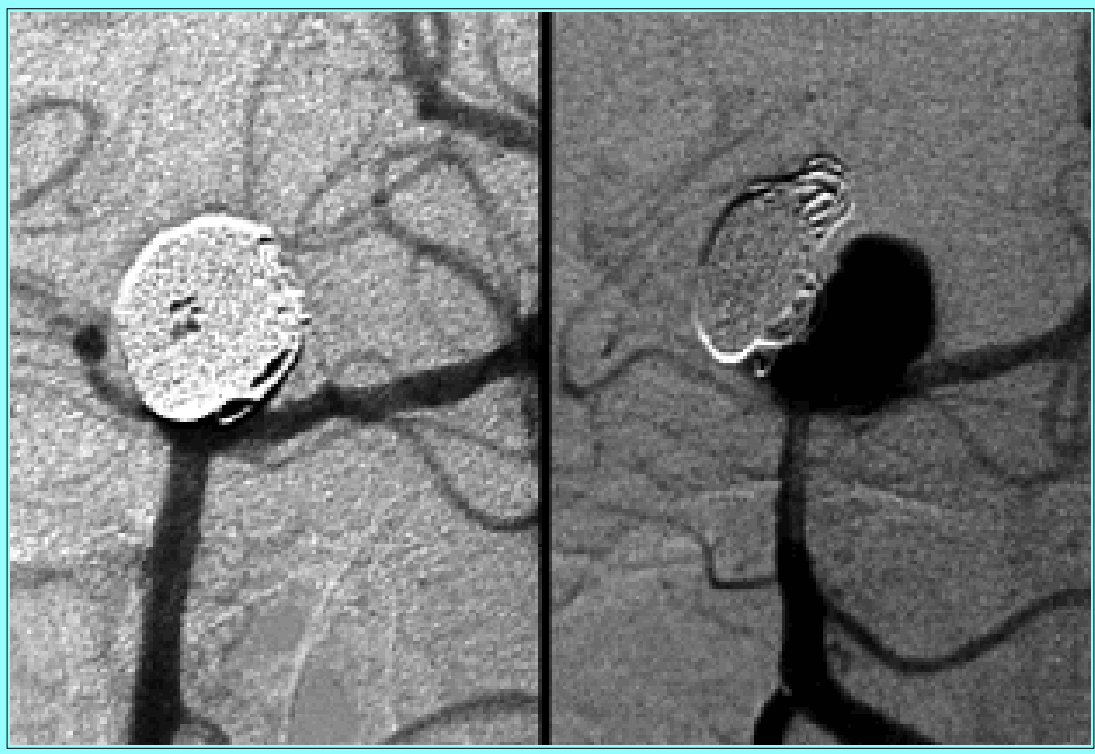

Fig. 2. Case 4 (Table 7). Intraarterial angiograms obtained after coil embolization (left) and 30 months later (right), following rebleeding. There is residual filling (left), which at the 6-month follow-up angiographic session consisted of an inflow pocket. Further coil compaction occurred, as there is a substantial recurrent aneurysm sac.

Three of these patients survived recurrent hemorrhage. Two were retreated by endovascular coiling and one by surgical clipping. All three made good recoveries. Thus three $(7.9 \%)$ of 38 aneurysms with an unstable occlusion and one (0.4\%) of 221 aneurysms with a stable occlusion observed on 6-month follow-up angiography later reruptured.

The overall survival rate and number of patients at risk during each follow-up year are presented in Table 8. Annual rebleeding rates were $0.8 \%$ in the 1 st year, $0.6 \%$ in the 2 nd year, and $2.4 \%$ in the 3 rd year (Table 9). No further rebleeding occurred in the 67 patients who were observed beyond 3 years (Table 9) and no rebleeding was documented in those patients who did not undergo follow-up angiography.

\begin{tabular}{|c|c|c|c|c|c|}
\hline \multicolumn{6}{|c|}{$\begin{array}{c}\text { TABLE } 8 \\
\text { PROBABLITY OF OYERALL SURYYAL BY FOLLOM-UP YEAR* } \\
\end{array}$} \\
\hline $\begin{array}{l}\text { Follow- } \\
U_{p} \mathrm{Y}_{\mathrm{r}}\end{array}$ & $\begin{array}{l}\text { No. of } \\
\text { Patients } \\
\text { atRisk }\end{array}$ & $\begin{array}{l}\text { No. of } \\
\text { Deaths }\end{array}$ & $\begin{array}{l}\text { Patierts } \\
\text { Cersored } \\
\text { During Yr }\end{array}$ & $\begin{array}{c}\text { Survival } \\
\text { Probability } \\
{[\%]}\end{array}$ & $\mathrm{SE}$ \\
\hline $\begin{array}{l}1 \\
2 \\
3 \\
4 \\
5 \\
6 \\
\end{array}$ & $\begin{array}{r}317 \\
234 \\
139 \\
69 \\
28 \\
5 \\
\end{array}$ & $\begin{array}{r}16 \\
3 \\
1 \\
1 \\
0 \\
0 \\
\end{array}$ & $\begin{array}{r}67 \\
92 \\
69 \\
40 \\
23 \\
5 \\
\end{array}$ & $\begin{array}{l}94.9 \\
93.3 \\
92.5 \\
89.4 \\
89.4 \\
89.4 \\
\end{array}$ & $\begin{array}{l}1.2 \\
1.5 \\
1.7 \\
3.5 \\
3.5 \\
3.5\end{array}$ \\
\hline
\end{tabular}




\begin{tabular}{|c|c|c|c|c|c|c|}
\hline & OBABLIT & OF REBLEE & $\begin{array}{l}\text { TABLE } \\
\text { DING DURII }\end{array}$ & $\mathrm{ACH} F O L$ & JP VE & \\
\hline $\begin{array}{l}\text { Follow- } \\
\text { Up Yr }\end{array}$ & $\begin{array}{l}\text { No. of } \\
\text { Patients } \\
\text { atRisk }\end{array}$ & $\begin{array}{l}\text { Incidence } \\
\text { of } \mathrm{Re} \\
\text { bleeding }\end{array}$ & $\begin{array}{l}\text { Patierts } \\
\text { Cersored } \\
\text { During Yr }\end{array}$ & $\begin{array}{l}\text { Survival } \\
\text { Proba bi- } \\
\text { lity (\%) }\end{array}$ & $\mathrm{SE}$ & $\begin{array}{c}\text { Rebleed- } \\
\text { ingRate } \\
\text { (\%) }\end{array}$ \\
\hline 1 & 317 & 2 & 82 & 99.2 & 0.5 & 0.8 \\
\hline 2 & 233 & 1 & 93 & 98.6 & 0.8 & 0.6 \\
\hline$\overline{3}$ & 139 & 2 & 70 & 96.2 & 1.9 & 2.4 \\
\hline 4 & 67 & 0 & 39 & 96.2 & 1.9 & 0 \\
\hline 5 & 28 & 0 & 23 & 96.2 & 1.9 & 0 \\
\hline 6 & 5 & 0 & 5 & 96.2 & 1.9 & 0 \\
\hline
\end{tabular}

\section{DISCUSSION}

The potential benefit of endovascular treatment to patients with recently ruptured intracranial aneurysms is protection from rebleeding at the minimum risk of iatrogenic morbidity. The arguments for avoiding craniotomy by exploiting the endovascular route after aneurysmal SAH have encouraged attempts to isolate aneurysms from the cerebral circulation by endosaccular packing with balloons, coils, and liquid embolic agents. Treatment results have been varied and have failed to convince many neurosurgeons that they are effective alternatives to microsurgical clipping in all but selected patients with high-risk aneurysms. This was hardly surprising when endosaccular embolization with balloons, for example, was associated with mortality rates as high as $18 \%$ for all patients[22] and $22 \%$ for those with small aneurysms.[47] However more recent reports of outcomes in patients treated by endosaccular packing with detachable coils[7,30,40,44,55] have challenged the view that microsurgical clipping remains the treatment of choice for all recently ruptured aneurysms. In this situation, the two treatment approaches need to be compared in a prospective randomized trial to avoid historical bias and, preferably, in a large multicenter study such as the ongoing ISAT to compare a broad range of technical expertise.

In the absence of such data, this study has been performed to assess medium-term outcomes and rebleeding risks for patients with intracranial aneurysms treated by coil embolization in the acute and recovery phases following rupture. It is important to bear in mind the demographic characteristics of our patients, which vary from those listed in previous surgical reports because patient selection was made on the basis of anticipated surgical difficulty and because of delays in patient transfers from other neurosurgical centers. The treated cohort thus contains a relatively large proportion of WFNS Grade 1 patients treated relatively long after $\mathrm{SAH}$, which would be expected to improve the overall outcome results, but may be counterbalanced by a higher proportion of posterior circulation aneurysms than most surgical series. Treatment outcomes in this study are similar to those of other endovascular series; Raymond and Roy[44] treated two thirds of their 75 patients within 48 hours of hemorrhage and reported excellent or good outcomes at 6 months in $72 \%$ of the patients. These results are also similar to recently reported series of patients treated by microsurgical clipping after aneurysmal SAH, in which excellent or good outcomes (GOS scores 4 and 5) were achieved in 74 to $89 \%$ of patients presenting with Hunt and Hess Grades I to III.[2,13,43,51] In a recent large prospective randomized study of tirilazad[21] involving 902 patients it was reported that 67 to $76 \%$ of patients with good outcome or moderate disability at 3 months, with more than $90 \%$ of the patients treated surgically. Among our patients, those with WFNS Grade IV or V at the time of treatment did particularly well when compared with surgical mortality rates of 35 to $45 \%$ reported by the International Cooperative Study in these subgroups.[26] 
Fundamental to the prognosis after aneurysmal SAH is the protection against rebleeding provided by any treatment. It has long been recognized that incomplete aneurysm obliteration by surgical clipping is associated with rebleeding[11,12] and that aneurysm neck remnants or rests can enlarge.[27] Incidences of incomplete aneurysm obliteration of approximately $4 \%$ have been reported on follow-up angiography.[3,12,15,27,29,32] Feuerberg, et al.,[15] found aneurysm rests in 3.8\% of 715 treated patients and, in a study of 66 patients, Macdonald and associates[29] unexpectedly found $4 \%$ of aneurysms that were incompletely clipped and another $4 \%$ totally unclipped on postoperative angiography. Regrowth and rebleeding may occur after apparently complete occlusion[27] and no constant rate of regrowth has been determined.[1,27] Aneurysm wrapping, on the other hand, is a far less secure method of protecting patients: Todd, et al.,[53] recorded an incidence of early rebleeding (within 6 months) of $8.6 \%$ and annual delayed rebleeding rates ranging from 1.5 to $4.5 \%$ have been reported.[37,53]

Angiographic findings after coil embolization should be considered against this background. However, it should be appreciated that some change in the degree of occlusion after the end-of-treatment angiogram is to be anticipated and comparisons with postclipping angiography are difficult. It is assumed that an aneurysm completely obliterated by a surgical clip is very unlikely to regrow. Residual filling of the lumen or neck region is more frequent after coil embolization and, even after complete initial occlusion, the degree of occlusion is not necessarily as stable. Angiographic follow-up examination, therefore, has to determine the completeness of the embolization and its stability over time. In the design of this study, we arbitrarily elected to perform follow-up angiography at 6 months. This interval was chosen to ensure that post-SAH vasospasm would not influence the degree of occlusion and that any tendency for aneurysm regrowth might be recognized. It also coincided with the end of the period in which patients are at highest risk of rebleeding.[56] Our results show that the degree of aneurysm obliteration changed over this period to a far greater extent than would be expected following aneurysm clipping; the completeness of obliteration improving in $8.5 \%$ and deteriorating in $14.7 \%$ of aneurysms.

Incomplete occlusion was present at some stage in all four patients who rebled from treated aneurysms. This is hardly surprising but disappointingly, the 6-month angiography session showed a stable remnant in one patient and failed to anticipate subsequent recurrence and rebleeding. Stable thrombosis has been demonstrated in experimental aneurysms constructed in various animal species and studied for up to 6 months;[6,35] however, as late as 6 months after treatment, Reul and colleagues[45] found a lack of organized thrombus around coils at the neck of bifurcation aneurysms in rabbits. There are few reports of human postmortem examinations[31,38,39] and these have shown poorly organized or unorganized intraaneurysmal thrombus. Coils that protruded into the recurrent lumen of a large PCoA aneurysm, reported by Manabe, et al.,[31] were covered only by a thin transparent membrane. These findings suggest that the coil-thrombus complex at orifices of larger aneurysms subjected to hemodynamic forces of axial blood flow fail to form a normal endothelial cell layer. It can, therefore, be speculated that some degree of neck reopening after coil embolization may be a benign consequence of thrombus organization and fibrosis around the coils because the majority of small and large aneurysms in this study remained stable over 6 months, although it is difficult to imagine that this process, once initiated, is not progressive.

This study supports previously reported observational studies that endosaccular coil embolization protects patients against rebleeding in the first 6 months.[7,17,30,40,44] However, care should be taken in this interpretation because the cohort contains a relatively small percentage of patients who were treated within 48 hours of bleeding and delaying treatment may select a subgroup at reduced risk of 
rebleeding. That patients treated by coil embolization up to now may have a lower risk of rebleeding is supported by the relatively high rate of incomplete occlusion following coil embolization. A neck or more substantial remnant was present in $36 \%$ of aneurysms in this study, but the single instance of rebleeding during this period was caused by rupture of an untreated coincidental aneurysm. Delayed ( $>6$ months) rebleeding after coil embolization has been previously reported.[9,30,31,44] These studies found that incomplete occlusion of the aneurysm lumen due to large size,[30] incomplete packing, $[9,44]$ and coil compaction leading to aneurysm recurrence[31] were causes. Follow-up angiography at 6 months in this study demonstrated more frequent instability in larger aneurysms but rebleeding, which was far less frequent, occurred in patients with both large and small aneurysms.

Rebleeding is a rare complication after microsurgical clipping, but has been reported to affect 0.5 to $2 \%$ of patients.[11,43,50-52] Feuerberg, et al.,[15] reported a 3.7\% incidence of rebleeding among patients with aneurysm rests observed for 8 years. They calculated an annual rebleeding risk of $0.38 \%$ in patients with incompletely clipped aneurysms and $0.79 \%$ in those with patent rests. In this study the same calculation (dividing the number of rebleeding patients by the number of follow-up years) gives an annual rebleeding rate of $0.82 \%$; however, this method tends to underestimate the rate and, in this instance, failed to identify the higher rate in Year 3 (Table 8). This latter finding supports the concept that coil compaction and aneurysm recurrence take time (probably > 6 months) to develop. The incidences of rebleeding ( $7.9 \%$ in patients with unstable aneurysms and $0.4 \%$ in those with stable occlusions), although high, do provide reassurance that complete occlusion is protective and do not suggest that regrowth and rebleeding are inevitable consequences of incomplete occlusion.

Long-term observational studies with large numbers of patients are needed to confirm the findings of this study and assess the time scale for postembolization aneurysm recurrence. The interval between clipping and rebleeding is often years: Giannotta and Litofsky[16] reported an average interval of 10.5 years and rebleeding due to regrowth has been reported as late as 17 years after clipping.[49] Longitudinal studies must, therefore, be prolonged. The large numbers of patients needed will require collaboration within multicenter trials or the establishment of national and international registers of treated patients. Although it is likely that the frequency of aneurysm recurrence after coil embolization will diminish as improvements are made in the design of coils, such as the recently introduced soft coils that allow denser packing, periodic follow-up angiography should be performed as part of the treatment plan. These studies are needed to exclude the occurrence of coil compaction and, should aneurysm regrowth occur, it warrants careful observation if not early retreatment (either by coil embolization or microsurgical clipping).

\section{Acknowledgments}

We would like to thank M. Clarke and J. Halsey of the Clinical Trial Service Unit, University of Oxford for performing the statistical analysis; W. Lim, F. Bacon, and R. Byrne for assistance in data collection; and R. Strachan for preparing the manuscript.

\section{References}

1. Allcock JM, Canham PB: Angiographic study of the growth of intracranial aneurysms. J Neurosurg 45:617-621, 1976

2. Auere LM: Unfavorable outcome following early surgical repair of ruptured cerebral aneurysms--a critical review of 238 patients. Surg Neurol 35:152-158,1991 
3. Barrow DL, Boyer KL, Joseph GJ: Intraoperative angiography in the management of neurovascular disorders. Neurosurgery 30:153-159, 1992

4. Bryan RN, Rigamonti D, Mathis JM: The treatment of acutely ruptured cerebral aneurysms: endovascular therapy versus surgery. AJNR 18:1826-1830, 1997

5. Byrne JV, Adams CBT, Kerr RSC, et al: Endosaccular treatment of inoperable intracranial aneurysms with platinum coils. Br J Neurosurg 9:585-592, 1995

6. Byrne JV, Hope JKA, Hubbard N, et al: The nature of thrombosis induced by platinum and tungsten coils in saccular aneurysms. AJNR 18:29-33, 1997

7. Byrne JV, Molyneux AJ, Brennen RP, et al: Embolisation of recently ruptured intracranial aneurysms. J Neurol Neurosurg Psychiatry 59:616-620, 1995

8. Casasco AE, Aymard A, Gobin YP, et al: Selective endovascular treatment of 71 intracranial aneurysms with platinum coils. J Neurosurg 79:3-10, 1993

9. Cognard C, Weill A, Costaings L, et al: Intracranial berry aneurysms: angiographic and clinical results after endovascular treatment. Radiology 206:499-510, 1998

10. Drake CG: Report of World Federation of Neurological Surgeons Committee on a universal subarachnoid hemorrhage grading scale. J Neurosurg 68:985-986, 1988 (Letter)

11. Drake CG, Allcock JM: Postoperative angiography and the "slipped" clips. J Neurosurg 39:683-679, 1973

12. Drake CG, Friedman AH, Peerless SJ: Failed aneurysm surgery. Reoperation in 115 cases. J Neurosurg 61:848-856, 1984

13. Edner G, Kågström E, Wallstedt L: Total overall management and surgical outcome after aneurysmal subarachnoid haemorrhage in a defined population. Br J Neurosurg 6:409-420, 1992

14. Fernandez Zubillaga A, Guglielmi G, Viñuela F, et al: Endovascular occlusion of intracranial aneurysms with electrically detachable coils: correlation of aneurysm neck size and treatment results. AJNR 15:815-820, 1994

15. Feuerberg I, Lindquist C, Lindqvist M, et al: Natural history of postoperative aneurysm rests. J Neurosurg 66:30-34, 1987

16. Giannotta SL, Litofsky NS: Reoperative management of intracranial aneurysms. J Neurosurg 83:387-393, 1995

17. Graves VB, Strother CM, Duff TA, et al: Early treatment of ruptured aneurysms with Guglielmi detachable coils: effects on subsequent bleeding. Neurosurgery 37:640-648, 1995

18. Guglielmi G, Viñuela F, Dion J, et al: Electrothrombosis of saccular aneurysms via endovascular approach. Part 2: Preliminary clinical experience. J Neurosurg 75:8-14, 1991

19. Guglielmi G, Viñuela F, Duckwiler G, et al: Endovascular treatment of posterior circulation aneurysms by electrothrombosis using electrically detachable coils. J Neurosurg 77:515-524, 1992 
20. Gurian JH, Viñuela F, Guglielmi G, et al: Endovascular embolization of superior hypophyseal artery aneurysms. Neurosurgery 39:1150-1156, 1996

21. Haley EC Jr, Kassell NF, Apperson-Hansen C, et al: A randomized, double-blind, vehicle-controlled trial of tirilazad mesylate in patients with aneurysmal subarachnoid hemorrhage: a cooperative study in North America. J Neurosurg 86:467-474, 1997

22. Higashida RT, Halbach VV, Barnwell SL, et al: Treatment of intracranial aneurysms with preservation of the parent vessel: results of percutaneous balloon embolization in 84 patients. AJNR 11:633-640, 1990

23. Hilal SK, Khandji A, Solomon RW: Obliteration of intracranial aneurysms with pre-shaped highly thrombogenic coils. Radiology 173:250-257, 1989

24. Hope JKA, Byrne JV, Molyneux AJ: Factors influencing successful angiographic occlusion of aneurysms treated by coil embolisation. AJNR (In press)

25. Jennett B, Bond M: Assessment of outcome after severe brain damage. A practical scale. Lancet 1:480-484, 1975

26. Kassell NF, Torner JC, Haley EC Jr, et al: The International Cooperative Study on the Timing of Aneurysm Surgery. J Neurosurg 73:18-36, 1990

27. Lin T, Fox AJ, Drake CG: Regrowth of aneurysm sacs from residual neck following aneurysm clipping. Part 1: Overall management results. J Neurosurg 70:556-560, 1989

28. Lindley RI, Waddell F, Livingstone M, et al: Can simple questions assess outcome after stroke? Cerebrovascular Dis 4:314-324, 1994

29. Macdonald RL, Wallace MC, Kestle JRW: Role of angiography following aneurysm surgery. J Neurosurg 79:826-832, 1993

30. Malisch TW, Guglielmi G, Viñuela F, et al: Intracranial aneurysms treated with the Guglielmi detachable coil: midterm clinical results in a consecutive series of 100 patients. J Neurosurg 87:176-183, 1997

31. Manabe H, Fujita S, Hatayawa T, et al: Rerupture of coil embolized aneurysm during long-term observation. Case report. J Neurosurg 88:1096-1098, 1998

32. Martin NA, Bentson J, Viñuela F, et al: Intraoperative digital subtraction angiography and the surgical treatment of intracranial aneurysms and vascular malformations. J Neurosurg 73:526-533, 1990 33. Massoud TF, Guglielmi G, Viñuela F, et al: Endovascular treatment of multiple aneurysms involving the posterior intracranial circulation. AJNR 17:549-554, 1996

34. Massoud TF, Guglielmi G Viñuela F, et al: Saccular aneurysms in Moyamoya disease: endovascular treatment using electrically detachable coils. Surg Neurol 41:462-467, 1994

35. Mawad ME, Mawad JK, Cartwright J Jr, et al: Long-term histopathologic changes in canine aneurysms embolized with Guglielmi detachable coils. AJNR 16:7-13, 1995

36. McDougall CG, Halbach VV, Dowd CF, et al: Endovascular treatment of basilar tip aneurysms using 
electrolytically detachable coils. J Neurosurg 84:393-399, 1996

37. Minakawa T, Koike T, Fujii Y, et al: Long term results of ruptured aneurysms treated by coating. Neurosurgery 21:660-663, 1987

38. Mizoi K, Yoshimoto T, Takahashi A, et al: A pitfall in the surgery of a recurrent aneurysm after coil embolization and its histological observation: technical case report. Neurosurgery 39:165-169, 1996

39. Molyneux AJ, Ellison DW, Morris J, et al: Histological findings in giant aneurysms treated with Guglielmi detachable coils. Report of two cases with autopsy correlation. J Neurosurg 83:129-132, 1995

40. Moret J, Pierot L, Boulin A, et al: Endovascular treatment of anterior communicating artery aneurysms using Guglielmi detachable coils. Neuroradiology 38:800-805, 1996

41. Murayama Y, Malisch T, Guglielmi G, et al: Incidence of cerebral vasospasm after early endovascular treatment of acutely ruptured aneurysms: report of 69 cases. J Neurosurg 87:830-835, 1997

42. Nichols DA: Endovascular treatment of the acutely ruptured intracranial aneurysm. J Neurosurg 79:1-2, 1993

43. Proust F, Hannequin D, Langlois $\mathrm{O}$, et al: Causes of morbidity and mortality after ruptured aneurysm surgery in a series of 230 patients. The importance of control angiography. Stroke 26:1553-1557, 1995

44. Raymond J, Roy D, Bojanowski M, et al: Endovascular treatment of acutely ruptured and unruptured aneurysms of the basilar bifurcation. J Neurosurg 86:211-219, 1997

45. Reul J, Weis J, Spetzger U, et al: Long-term angiographic and histopathologic findings in experimental aneurysms of the carotid bifurcation embolized with platinum and tungsten coils. AJNR 18:35-42, 1997

46. Richling B, Bavinzski G, Gross C, et al: Early clinical outcome of patients with ruptured cerebral aneurysms treated by endovascular (GDC) or microsurgical techniques. Intervent Neuroradiol 1:19-27, 1995

47. Romodanov AP, Shcheglov VI: Intravascular occlusion of saccular aneurysms of the cerebral arteries by means of a detachable balloon catheter. Adv Tech Stand Neurosurg 9:25-48, 1982

48. Rowe JG, Molyneux AJ, Byrne JV, et al: Endovascular treatment of intracranial aneurysms: a minimally invasive approach with advantages for elderly patients. Age Ageing 25:372-376, 1996

49. Sakaki T, Takeshima T, Tominaga M, et al: Recurrence of ICA-PCoA aneurysms after neck clipping. J Neurosurg 80:58-63, 1994

50. Sato S, Suzuki J: Prognosis in cases of intracranial aneurysm after incomplete direct operations. Acta Neurochir 24:245-252, 1971

51. Säveland H, Hillman J, Brandt L, et al: Overall outcome in aneurysmal subarachnoid hemorrhage. A prospective study from neurosurgical units in Sweden during a 1-year period. J Neurosurg 76:729-734, 1992 
52. Sundt TM Jr, Whisnant JP: Subarachnoid hemorrhage from intracranial aneurysms: surgical management and natural history of disease. N Engl J Med 299:116-122, 1978

53. Todd NV, Tocher JL, Jones PA, et al: Outcome following aneurysm wrapping: a 10-year follow-up review of clipped and wrapped aneurysms. J Neurosurg 70:841-846, 1989

54. Tress B, Mitchell P: Endovascular treatment of intracranial aneurysms. J Clin Neurosci 2:24-25, 1995

55. Viñuela F, Duckwiler G, Mawad M: Guglielmi detachable coil embolization of acute intracranial aneurysm: perioperative anatomical and clinical outcome in 403 patients. J Neurosurg 86:475-482, 1997 56. Winn HR, Richardson AE, Jane JA: The long-term prognosis in untreated cerebral aneurysms: 1 . The incidence of late haemorrhage in cerebral aneurysm: a 10-year evaluation of 364 patients. Ann Neurol 1:358-370, 1977

Manuscript received July 1, 1998.

Accepted in final form November 11, 1998.

Address reprint requests to: James Byrne, M.D., F.R.C.S., F.R.C.R., Department of Radiology, The Radcliffe Infirmary NHS Trust, Woodstock Road, Oxford, England, OX2 6HE, United Kingdom. email: james.byrne@radiology.ox.ac.uk. 